\title{
Kinetics modeling of alginate alkaline extraction from Laminaria digitata
}

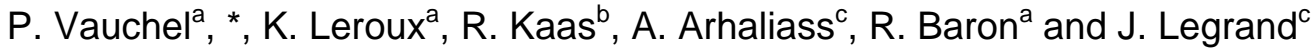 \\ a IFREMER, Département Sciences et Techniques Alimentaires Marines, rue de l'lle d'Yeu, BP21105, 44311 \\ Nantes Cedex 03, France \\ b IFREMER, Département Biotechnologie Marine, rue de l'lle d'Yeu, BP21105, 44311 Nantes Cedex 03, France \\ ${ }^{c}$ GEPEA, CNRS, Université de Nantes, UMR 6144, CRTT, BP406, 37 bd de I'Université, 44602 Saint-Nazaire \\ Cedex, France
}

*: Corresponding author: P. Vauchel, Tel.: +33 (0) 2403741 03; fax: +33 (0) 2403740 71, email address : peggy.vauchel@univ-nantes.fr

\begin{abstract}
:
Alginates being depolymerized during their alkaline extraction, reducing extraction time could help producing higher rheological quality alginates. The purpose of the present work is to study fresh Laminaria digitata destructuration during alkaline extraction and its link to extraction kinetics. Both alginate extraction yield and mean diameter of algae particles were followed for different values of agitation level and initial size of algae pieces. Results highlighted the existence of a link between extraction yield and algal destructuration. Those elements and the specificity of $L$. digitata structure have been taken into account to propose a kinetics model based on a fluid-particle reaction with decreasing size particles. The model parameters have been adjusted thanks to acquisition data and its predictive capacity was assessed by validation data. Provided predictions appeared to be relevant and the model structure suitability was confirmed, as extraction yield kinetics specific shape was quite reliably described.
\end{abstract}

Keywords: Alginate; Alkaline extraction kinetics; Laminaria digitata; Model 


\section{Introduction}

Alginates are naturally present in the cell wall of brown seaweeds (Kloareg \& Quatrano, 1988). These polysaccharides show interesting rheological properties : they enable to enhance aqueous solutions viscosity at low concentration, and to form gels or thin films. They are widely used in various fields of industry : textile, food, paper, cosmetics, pharmaceuticals industries... (Pérez et al., 1992). Alginate industry extraction protocol is basically divided into five steps : acidification, alkaline extraction, solid/liquid separation, precipitation and drying (Fig. 1). Acidification consists in immersing seaweeds in a sulphuric acid bath (about $0.5 \mathrm{~N}$ ) for several hours so as to convert insoluble alginate salts present in the cell walls into alginic acid. Alkaline extraction is the central step as it corresponds to the extraction phase itself. Acidified seaweeds are soaked in a sodium carbonate solution : insoluble alginic acid is converted into soluble sodium alginate, which passes into the aqueous phase. It requires several hours to reach the optimum extraction yield, depending on the seaweed species considered (Pérez, 1997). Seaweed residues are then separated from the sodium alginate solution using floatation/flocculation and filtration. Sulphuric acid or calcium chloride or is then added so as to precipitate alginates in their acid or calcium salt form respectively, the latter one being easier to dewater. The product is afterwards pressed and dried by heating. The different alginate salts are finally produced by making alginic acid react with the appropriate base.

A previous work highlighted a decrease of dynamic viscosity and average molecular weight during alkaline extraction of alginates from Laminaria digitata (Vauchel et al., 2008). This depolimerization phenomenon seems to be principally due to $\mathrm{pH}$ and temperature effects (Hernandez et al., 1999b) . Bacterial development and endogenous alginate lyases activities are also mentionned (Moen et al., 1997; Smidsrød et al., 1963). The most evident solution from the industrial point of view to avoid these depolymerization phenomena would be to reduce the extraction time. Some works have been conducted on alginate extraction process, but most of them deal with pre-extraction steps or final steps like conversion of alginic acid to alginate salts, drying and milling (Wedlock \& Fasihuddin, 1990; Arvizu-Higuera et al., 1997; Hernandez-Carmona et al., 1999a; Hernandez-Carmona et al., 2002; Myklestad, 1968). Only few focus on the alkaline extraction step. Arvizu-Higuera et al.(2002) and Hernandez-Carmona et al.(1999b) have worked on this step but both on dried and milled Macrocystis pyrifera.

To the best of our knowledge, no work on the alkaline extraction of alginate from fresh algae has been published, whereas an important part of algae used in the alginate industry are fresh Laminariales. The purpose of the present work is to study algae destructuration and its link to extraction kinetics. Indeed, alkaline extraction may be mostly limited by algal structure and most of the required time for alkaline extraction of alginates may correspond to algal destructuration. Assessments on influent parameters and mathematical modelling of extraction yield kinetics of alginate from fresh Laminaria digitata are investigated in this study. A set of alkaline extraction experiments was conducted to follow both alginate extraction yield and mean diameter of algae particles, the latter being used as an intermediary parameter in the proposed model.

\section{Material and methods}

\section{Alkaline extraction experiments}

All experiments were conducted on Laminaria digitata fronds harvested in Portsall, Brittany, France, and stored in a $2 \%(\mathrm{w} / \mathrm{w})$ formalin solution to ensure their preservation during stocking (4 months). Algae pieces were punched out of several two year old entire fronds in 
order to minimize heterogeneity problems like variation of alginate content in function of the frond and in function of the part of the frond (Pérez, 1970). The extraction protocol was a laboratory adaptation of the industrial process described by Pérez et al. (1992): algae pieces were rinsed to eliminate formalin and then immersed in a $0.5 \mathrm{M} \mathrm{H} 2 \mathrm{SO} 4$ solution for at least one night (stored at $4^{\circ} \mathrm{C}$ ). For each extraction experiment, $50 \mathrm{~g}$ of algae pieces were rinsed with distilled water and soaked in $1 \mathrm{~L}$ of a $4 \%(\mathrm{w} / \mathrm{w}) \mathrm{Na2 \textrm {CO }}$ solution under continuous stirring (12 cm diameter $2 \mathrm{~L}$ beaker with a $4 \mathrm{~cm}$ long magnetic stirrer) at room temperature $\left(20^{\circ} \mathrm{C}\right)$. Samples were taken regularly : algae residues were separated from the supernatant using a nylon filter sheet and stored in a $1 \%(\mathrm{w} / \mathrm{w})$ formalin solution at $4^{\circ} \mathrm{C}$ until image analysis ; the supernatant was used to determine the extraction yield. For acquisition data, experiments were conducted for 3 different diameters of algae discs, 8,16 and $30 \mathrm{~mm}, 3$ different stirring levels, 200, 500 and $800 \mathrm{rpm}$, and samples were taken for 15, 30, 45, 60, $90,120,150,180,210,240,270$ and $300 \mathrm{~min}$ extraction time. For validation data, experiments were conducted for 2 different diameters of algae discs, 40 and $100 \mathrm{~mm}$, and 2 different stirring levels, 100 and $500 \mathrm{rpm}$. Samples were taken for 15, 30, 45, 60, 90, 120, $150,180,210,240,270,300,360,420$ and $420 \mathrm{~min}$ extraction time for $40 \mathrm{~mm}$ diameter algae discs. Additional samples were taken for 540,600,660, 720, 780, 840 and 900 min extraction time for $100 \mathrm{~mm}$ diameter algae discs.

For experiments conducted on medulla and cortex tissues, the extraction protocol was nearly the same. Medulla and cortex tissues were manually separated by means of a scalpel and stored in a $0.5 \mathrm{M} \mathrm{H} 2 \mathrm{SO} 4$ solution at $4^{\circ} \mathrm{C}$ for at least one night. For each extraction experiment, $2.5 \mathrm{~g}$ of tissue were rinsed with distilled water and immersed in $50 \mathrm{~mL}$ of a $4 \%$ (w/w) Na2CO3 solution under continuous stirring. Supernatant samples were taken regularly in order to follow the extraction yield until reaching its final value.

\section{Determination of the extraction yield}

Sodium alginate content of the supernatant was quantified for each sample according to Kennedy \& Bradshaw (1984) protocol. A $20 \%$ (w/v) $\mathrm{PHMB}+\mathrm{Cl}-$ (polyhexamethylenebiguanidium chloride) commercial solution (provided by Bayrol France S.A.) was diluted in a $1 \%(\mathrm{w} / \mathrm{v})$ sodium acetate solution. Ten milliliter of this $0.3 \%(\mathrm{w} / \mathrm{v})$ $\mathrm{PHMB}+\mathrm{Cl}$ - solution were stirred with $5 \mathrm{~mL}$ of sample supernatant for $5 \mathrm{~min}$ before centrifugation (5000 g, $10 \mathrm{~min}$ ) to separate the precipitate from the supernatant. Absorbance read at $235 \mathrm{~nm}$ against distilled water of the 100 times diluted supernatant was measured. Sodium alginate concentration was obtained thanks to a calibration curve. A commercial NaAlg (Sigma) was used to determine the calibration curve. Extraction yield was calculated as the ratio of the dry weight of alginic acid extracted to the dry weight of algae used for the extraction.

\section{Determination of the mean diameter of algae particles}

Algae residues size was determined using image analysis. Samples were placed on a Petri dish lying on a transparency viewer. A picture was taken and the image analysed by means of SAMBA software (TITN Alcatel). Grey scale images were binarized thanks to a threshold segmentation algorithm and objects were tagged and numbered so as to obtain the surface histogram. Russ (2006) has given a detailed description of these classical image processing algorithms. The mean diameter of algae residues for each sample was calculated by approximating their shape to a disc. 


\section{Results and discussion}

\section{Study of the alkaline extraction}

A previous work showed that alkaline extraction duration has an influence on the rheological quality of alginates produced (Vauchel et al., 2008). It also seemed interesting to study the extraction reaction kinetics, so as to find solutions to reduce its duration while maintaining a maximum extraction yield. Preliminary experiments enabled to identify two parameters having a significant influence on the extraction duration, the agitation level and the initial size of algae pieces. Temperature effect should also be taken into account, but we chose in this work to consider a fixed temperature (room temperature). A set of experiments was conducted to assess the respective weight of agitation level and initial size of algae pieces effects. The extraction yield and the mean diameter of algae pieces were measured during the alkaline extraction, for 3 initial sizes of algae pieces $(8,16$ and $30 \mathrm{~mm}$ diameter algae discs) and 3 stirring levels (200, 500 and $800 \mathrm{rpm})$. Results are displayed in Fig. 2. First, it has to be noticed that there is no significant variation of the final extraction yield in function of the experiment (Table 1), showing that no significant heterogeneity problem was encountered.

No equivalent experiment being available in literature, kinetics results obtained in this work cannot be directly compared to previous works. The most relevant compairison that can be made is with Hernández-Carmona et al. (1999b) work. In this work, alkaline extractions were conducted on rehydrated milled Macrocystis pyrifera at $70-90^{\circ} \mathrm{C}$ with no stirring. The closest experiments within ours may be those conducted with the smallest algae pieces $(8 \mathrm{~mm}$ diameter) and the lower stirring level (200 rpm). It appears that about 3 hours are required to reach the maximum extraction yield in both cases. Hence, even if experiment conditions are not exactly the same, characteristic times of extraction kinetics seem to be of the same order.

Curves shapes highlight the influence of both stirring level and size of algae pieces on the extraction kinetics : at low stirring level, the initial size of algae pieces is highly influent, whereas at high stirring level, this parameter is no more significant. Moreover, there is obviously a link between algae destructuration and extraction yield. With specific adjustments (small algae pieces and high stirring level), algal destructuration could be accelerated. The extraction time would be shortened and high rheological quality alginates would be produced.

\section{Modeling of the alkaline extraction kinetics}

The aim being to control alginate extraction time, it seemed interesting to establish a model for the prediction of extraction kinetics in function of parameters identified as the most influent, stirring level and size of algae pieces. A model, taking into account comprehensive aspects is considered. The proposed model is based on the fact that the alkaline extraction can be considered as a fluid-particle reaction, with decreasing size particles. The reaction rate is associated to algal alginate availability i.e. to algae particles size. However, algae particles cannot be considered as an homogenous material : Laminaria digitata tissue is composed of two different parts, the inner one called medulla and the outer one called cortex. Schematically, the medulla is a "soft" tissue composed of uncoloured and unstructured cells, whereas the cortex is a more "rigid" tissue composed of smaller, coloured and well structured cells. Those structural differences were taken into account to build the model, which is presented below. As they may lead to different extraction rates, extraction yield kinetics of the two kind of tissue were modelled separately (Equations 1 and 2), the total extraction yield being the sum of each specific extraction yield (Equation 3). Extraction yield kinetics equations have been built on the basis of a classical first order reaction equation (Equation 4), ie an exponential function tending towards the maximum extraction yield value Rmax with a characteristic time. The particularity of the proposed equation is that the 
characteristic time depends on destructuration kinetics via the time-evolution of the algae diameter $\mathrm{D}(\mathrm{t})$, the being modelled according to Equation 5 .

$$
\begin{aligned}
& \frac{d R_{\text {med }}(t)}{d t}=\frac{K_{\text {med }}}{D(t)} \cdot\left[R_{\text {max med }}-R_{\text {med }}(t)\right] \\
& \frac{d R_{\text {cort }}(t)}{d t}=\frac{K_{\text {cort }}}{D(t)} \cdot\left[R_{\text {max cort }}-R_{\text {cort }}(t)\right] \\
& R(t)=R_{\text {max }} \cdot\left[1-\exp \left(-\frac{t}{\tau}\right)\right] \\
& R_{\text {tot }}(t)=R_{\text {med }}(t)+R_{\text {cort }}(t) \\
& \frac{d D(t)}{d t}=-K_{D} \cdot\left[D(t)-D_{\text {min }}\right]^{2}
\end{aligned}
$$

$\mathrm{R}_{\text {med }}(\mathrm{t})$ and $\mathrm{R}_{\text {cort }}(\mathrm{t})(\%)$ are extraction yields associated to alginates present in the medulla and in the cortex respectively, $R_{\text {tot }}(t)(\%)$ is the total extraction yield, $R_{\text {maxmed }}$ and $R_{\text {maxcort }}(\%)$ are final extraction yields associated to alginates present in the medulla and in the cortex respectively, $R_{\max }(\%)$ is the final extraction yield for the whole algae (sum of $R_{\operatorname{maxmed}}$ and $\left.R_{\text {maxcort }}\right), K_{\text {med }}$ and $K_{\text {cort }}\left(\mathrm{m} \mathrm{s}^{-1}\right)$ are factors associated to extraction yield kinetics of the medulla and cortex parts respectively, $\mathrm{D}(\mathrm{t})(\mathrm{mm})$ is the mean diameter of algae particles, $D_{\min }(\mathrm{mm})$ is the final mean diameter of algae particles, $D_{0}(\mathrm{~mm})$ is the initial diameter of algae pieces and $\mathrm{K}_{\mathrm{D}}\left(\mathrm{s}^{-1}\right)$ is the factor associated to mean diameter kinetics.

$\mathrm{K}_{\text {med }}, \mathrm{K}_{\text {cort }}$ and $\mathrm{K}_{\mathrm{D}}$ were adjusted thanks to acquisition data (initial algae diameter, $\mathrm{D}_{0}=8,16$ and $30 \mathrm{~mm}$; impeller rotation speed, $S=200,500$ and $800 \mathrm{rpm}$ ). Different models were tested with $D_{0}$ and $S$ as predictive factors (least square method). Analysis of variance results showed that $\mathrm{K}_{\mathrm{D}}$ depends both on the stirring level and the initial size of algae pieces, whereas $\mathrm{K}_{\text {med }}$ and $\mathrm{K}_{\text {cort }}$ only depend on the stirring level. Selected models and associated variance analysis results are displayed in Equations 6, 7 and 8 and in Table 2.

$$
\begin{aligned}
& K_{\text {med }}=\exp (-2.0854+0.0023 \cdot S) \\
& K_{\text {cort }}=\exp (-3.8824+0.0017 \cdot S) \\
& K_{D}=\exp \left(-3.7177-0.0344 \cdot D_{0}+0.0006 \cdot S\right)
\end{aligned}
$$

Additional experiments were conducted in order to estimate $R_{\text {maxmed }}$ and $R_{\text {maxcort }}$ values. Medulla and cortex tissues were separated and alkaline extractions were conducted on each part, so as to estimate the ratio of each kind of tissue in the whole algae and the alginate content of each part. Results are displayed in Table 3. Globally, it can be assessed that $46 \%$ of the final alginate extraction yield is associated to medulla tissue and $54 \%$ is associated to cortex tissue for the Laminaria digitata fronds used in this study. Finally, $R_{\operatorname{maxmed}}$ and $\mathrm{R}_{\operatorname{maxcort}}$ values were estimated according to Equations 9 and 10.

$$
\begin{aligned}
& R_{\max m e d}=0.46 \cdot R_{\max } \\
& R_{\operatorname{maxcort}}=0.54 \cdot R_{\max }
\end{aligned}
$$

Predictions provided by the proposed model for acquisition data (D0=8, 16 and $30 \mathrm{~mm}$; $\mathrm{S}=200,500$ and $800 \mathrm{rpm}$ ) are presented on Figure 3. Globally, predictions were quite close to acquisition data, particularly for mean diameter data. Concerning extraction yield curves, small differences can be observed in some cases. When $S=500 \mathrm{rpm}$, the model slightly overestimates extraction yields for $\mathrm{D} 0=16 \mathrm{~mm}$ and $\mathrm{D} 0=30 \mathrm{~mm}$;; whereas at $\mathrm{S}=800 \mathrm{rpm}$, extraction yields are a little underestimated by the model for $D 0=16 \mathrm{~mm}$ and $\mathrm{D} 0=30 \mathrm{~mm}$ 
(percentage deviation is in all cases lower than 7\%). But estimated extraction times are globally quite close to reality.

\section{Model validation}

Validation data enabled to test the predictive capacity of the model. Additional alkaline extractions were conducted to get extraction yield data for four new D0-S couples : $\mathrm{D} 0=40$ or $100 \mathrm{~mm}$ and $\mathrm{S}=100$ or $500 \mathrm{rpm}$. Validation data and model predictions are presented on Figure 3. Globally, predictions are quite close to validation data but some differences can be observed and seem to grow while $S$ decreases and $D_{0}$ increases : the more time the extraction requires, the less the prediction is precise. Yet, these inaccuracies only concern the rising phase. Actually, extraction time estimations of the model are rather close to reality. The model provides quite good predictions even for parameters values that are quite far from the acquisition field. Moreover, it has to be noticed that extraction yield curves present a "S" shape during the rising phase. This couldn't have enabled it described by a first order model, whereas the proposed model is able to do it quite well, which confirms the model structure suitability.

\section{Conclusion}

The alkaline extraction step of the alginate production process was studied for fresh Laminaria digitata material. A set of extraction yield and destructuration kinetics were assessed for different values of two parameters identified as being significantly influent, the stirring level and the size of algae pieces. A new model was proposed in order to predict the extraction yield kinetics in function of these two parameters, taking into account the evolution of algae particles size and the two kind of tissues composing the algae. Validation phase showed that the proposed model is able to predict quite precisely the time required to reach the maximum extraction yield for a large set of initial algae diameter (DO) and impeller rotation (S) values. It could help shortening extraction time whilst producing high quality alginates, which could be of interest from an industrial point of view. However, a fixed temperature is considered in this work. Hence, the proposed model corresponds to a first step in the extraction kinetics modelling, which should be completed taking into account temperature effect.

\section{References}

Arvizu-Higuera, D.L., Hernández-Carmona, G. \& Rodríguez-Montesinos, Y.E. 1997. Effect of the type of precipitation on the process to obtain sodium alginate : calcium alginate method and alginic acid method. Ciencias Marinas. 23:195-207.

Arvizu-Higuera, D.L., Hernández-Carmona, G. \& Rodríguez-Montesinos, Y.E. 2002. Parameters affecting the conversion of alginic acid to sodium alginate. Ciencias Marinas. 28:27-36.

Hernández-Carmona, G., McHugh, D.J., Arvizu-Higuera, D.L. \& Rodríguez-Montesinos, Y.E. 1999a. Pilot plant scale extraction of alginates from Macrocystis pyrifera. 1. Effect of preextraction treatments on yield and quality of alginate. Journal of Applied Phycology. 10:507513.

Hernández-Carmona, G., McHugh, D.J. \& López-Gutiérrez, F. 1999b. Pilot plant scale extraction of alginates from Macrocystis pyrifera. 2. Studies on extraction conditions and methods of separating the alkaline-insoluble residue. Journal of Applied Phycology. 11:493502. 
Hernández-Carmona, G., McHugh, D.J., Arvizu-Higuera, D.L. \& Rodríguez-Montesinos, Y.E. 2002. Pilot plant scale extraction of alginates from Macrocystis pyrifera. 4. Conversion of alginic acid to sodium alginate, drying and milling. Journal of Applied Phycology. 14:445-451. Hernández-Carmona, G., Vilchis, M.A. \& Rodríguez-Montesinos, Y.E. 2002. Recirculation of residual acid from the pre-extraction stage in the process of obtaining sodium alginate. Ciencias Marinas. 18:125-137.

Kennedy, J.F. \& Bradshaw, I.J. 1984. A rapid method for the assay of alginates in solution using polyhexamethylenebiguanidium chloride. British Polymer Journal. 16:95-101.

Kloareg, B. \& Quatrano, R.S. 1988. Structure of the cell walls of marine algae and ecophysiological functions of the matrix polysaccharides. Oceanogr. Mar. Biol. Annu. Rev. 26:259-315.

Moen, E., Larsen, B. \& Ostgaard, K. 1997. Aerobic microbial degradation of alginate in Laminaria hyperborea stipes containing different levels of polyphenols. J. Applied Phycology. 9:45-54.

Myklestad, S. 1968. Ion-exchange properties of brown algae. I. Determination of rate mechanism for calcium-hydrogen ion exchange for particles from Laminaria hyperborea and Laminaria digitata. J. Applied Chem. 18:30-36.

Pérez, R. 1970. Teneur en acide alginique et degré de polymérisation de ce produit au cours de la vie de Laminaria digitata (L.) Lamour. Rev. Trans. Inst. Pêches Marit. 34:351-361.

Pérez, R., Kaas, R., Campello, F., Arbault, S. \& Barbaroux, O. 1992. La culture des algues marines dans le monde. Editions IFREMER, Plouzané, France, 613 pp.

Pérez, R. 1997. Ces algues qui nous entourent. Conception actuelle, rôle dans la biosphère, utilisations, culture. Editions IFREMER, Plouzané, France, 272 pp.

Smidsrød, O., Haug, A. \& Larsen, B. 1963. The influence of reducing compounds on the rate of degradation of alginates. Acta Chem. Scand. 17:1473-1474

Vauchel, P., Arhaliass, A., Legrand, J., Kaas, R. \& Baron R. 2008. Decrease in dynamic viscosity and average molecular weight of alginates from Laminaria digitata during alkaline extraction. J. Phycology. 44:in press.

Wedlock, D.J. \& Fasihuddin, B.A. 1990. Effect of formaldehyde pre-treatment on the intrinsic viscosity of alginate from various brown seaweeds. Food Hydrocolloids. 4:41-47. 


\section{Figures}

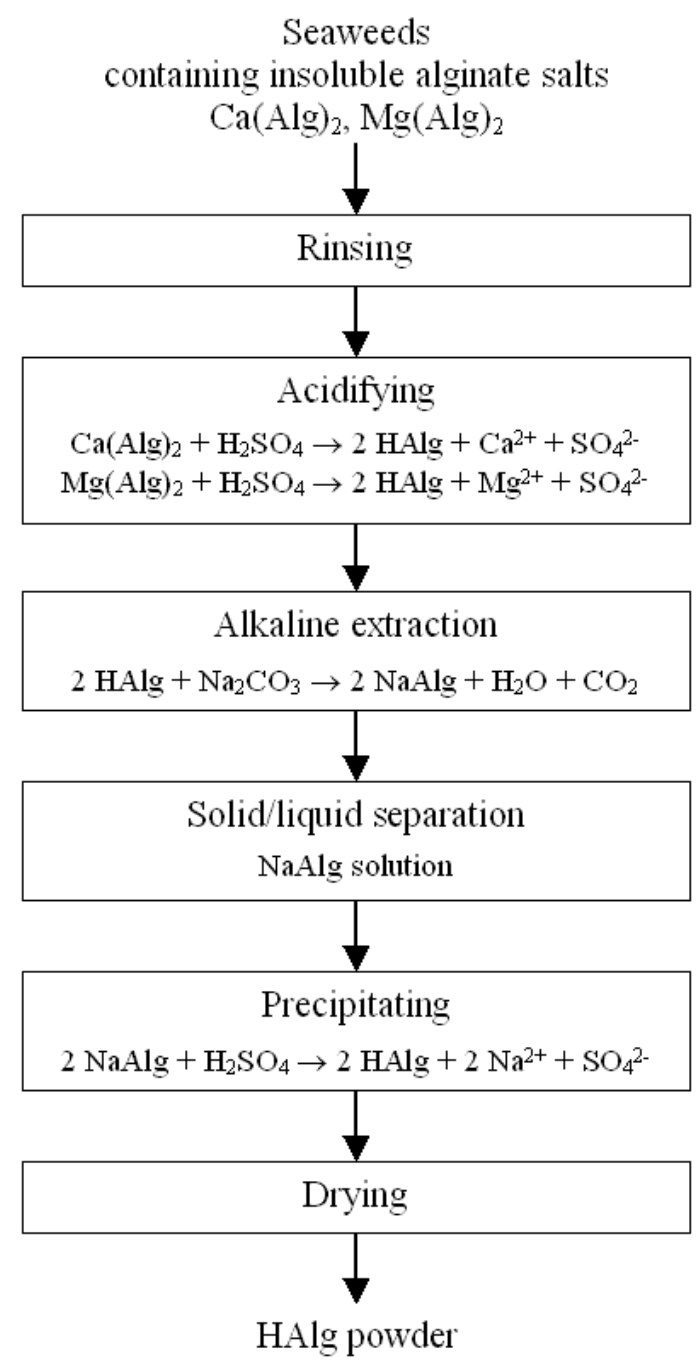

Fig. 1. Industrial direct method for alginate extraction (Pérez et al., 1992). HAlg : alginic acid; $\mathrm{NaAlg}$ : sodium alginate; $\mathrm{Mg}(\mathrm{Alg})_{2}$ : magnesium alginate; $\mathrm{Ca}(\mathrm{Alg})_{2}$ : calcium alginate. 

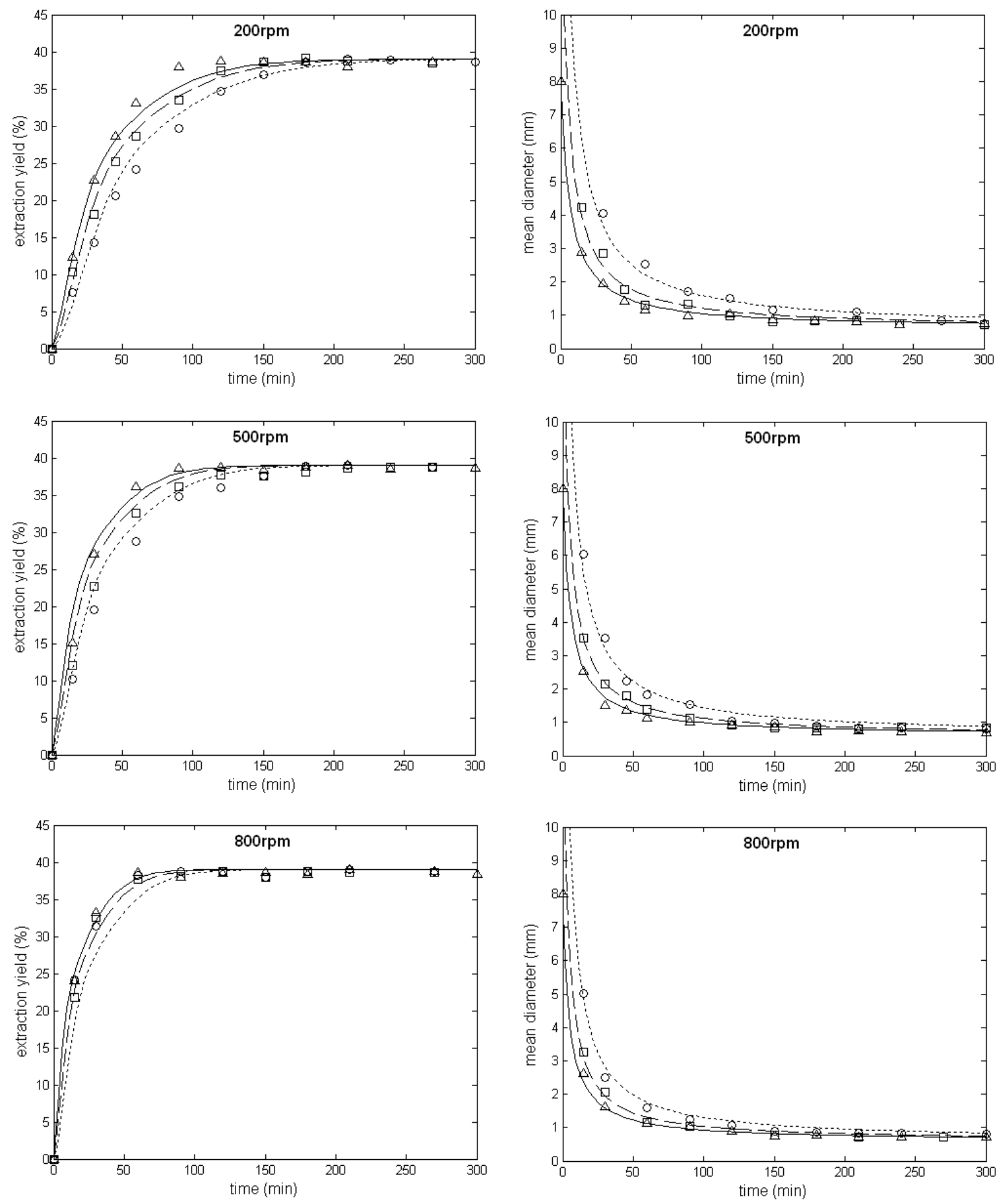

Fig. 2. Acquisition data and model predictions for the extraction yield and the mean diameter of algae particules during the alkaline extraction of alginates from Laminaria digitata for different stirring levels $(200,500$ and $800 \mathrm{rpm})$ and different initial diameter of algae pieces $(8,16$ and $30 \mathrm{~mm})$. Acquisition data are plotted with symbols $(\Delta 8 \mathrm{~mm} ; .16 \mathrm{~mm} ; 030 \mathrm{~mm})$ and model predictions are plotted with lines $(-8 \mathrm{~mm} ;--16 \mathrm{~mm} ;-30 \mathrm{~mm})$. 

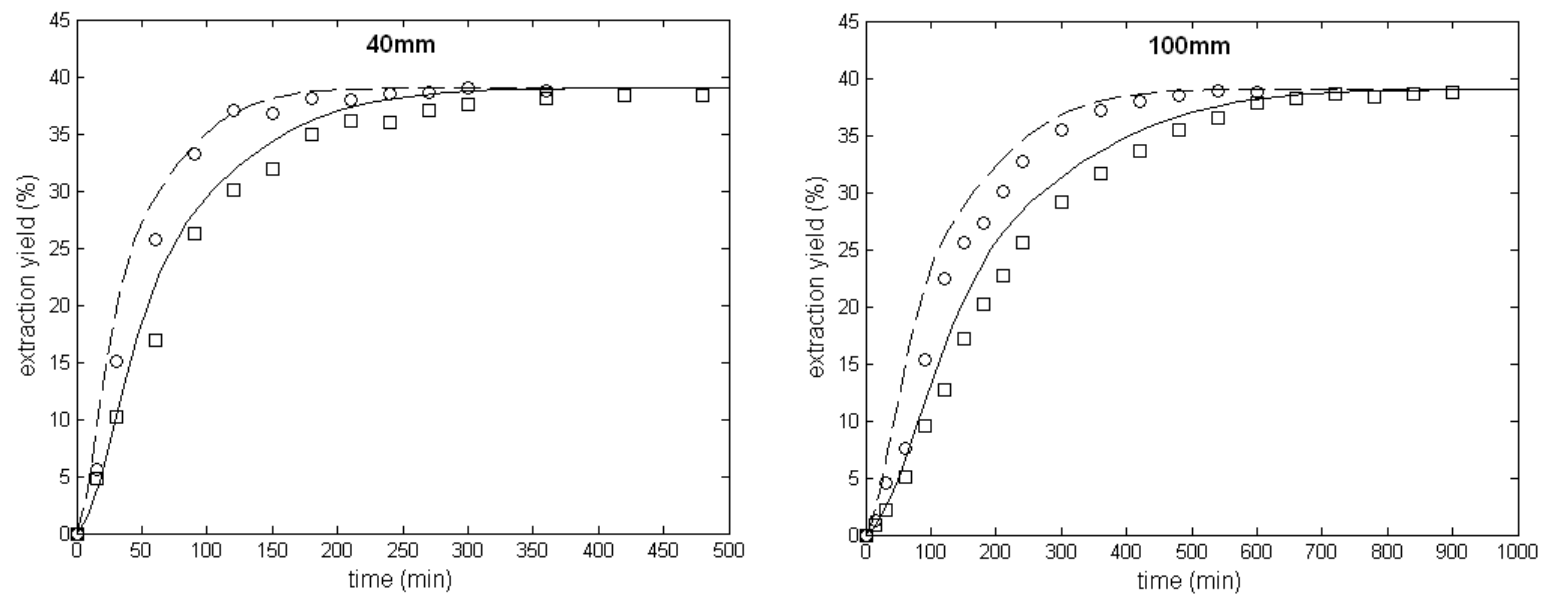

Fig. 3. Validation data and model predictions for the extraction yield during the alkaline extraction of alginates from Laminaria digitata for two stirring levels (100 and $500 \mathrm{rpm})$ and two initial diameter of algae pieces $(40$ and $100 \mathrm{~mm}$ ). Validation data are plotted with symbols ( $\square 100 \mathrm{rpm} ;$ O $500 \mathrm{rpm})$ and model predictions are plotted with lines (- $100 \mathrm{rpm}$; - $500 \mathrm{rpm})$.

\section{Tables}

Table 1. Final extraction yields for acquisition data (average value of the three last samples for each experiment).

\begin{tabular}{lll}
\hline Stirring level $(\mathrm{rpm})$ & $\begin{array}{l}\text { Initial diameter of algae } \\
\text { pieces }(\mathrm{mm})\end{array}$ & $\begin{array}{l}\text { Final extraction yield } \\
(\%)\end{array}$ \\
\hline 200 & 8 & 38.37 \\
& 16 & 38.81 \\
& 30 & 38.80 \\
\hline 500 & 8 & 38.72 \\
& 16 & 38.71 \\
\hline 800 & 30 & 38.81 \\
\hline & 16 & 38.68 \\
& 30 & 38.66 \\
Average final extraction yield (standard deviation) & 38.82 \\
\hline
\end{tabular}


Table 2. Selected linear models for $\mathrm{K}_{\text {med }}, \mathrm{K}_{\text {cort }}$ and $\mathrm{K}_{\mathrm{D}}$ and associated variance analysis results.

\begin{tabular}{lllll}
\hline & Model & $\begin{array}{l}\text { Predictive factors } \\
\text { (probability) }\end{array}$ & $\begin{array}{l}\text { Coefficients } \\
\text { (with 95\% } \\
\text { bounds) }\end{array}$ & $\begin{array}{c}\text { estimation } \\
\text { confidence }\end{array}$ \\
\hline $\mathrm{K}_{\text {med }}$ & $\ln \left(K_{\text {med }}\right)=a_{0}+a_{1} \cdot S$ & $\mathrm{~S}(0.0001)$ & $\begin{array}{l}\mathrm{a}_{0}=-2.0854 \\
\mathrm{a}_{1}=0.0023\end{array}$ & 0.9954 \\
\hline $\mathrm{K}_{\text {cort }}$ & $\ln \left(K_{\text {cort }}\right)=b_{0}+b_{1} \cdot S$ & $\mathrm{~S}(0.0001)$ & $\begin{array}{l}\mathrm{b}_{0}=-3.8824 \\
\mathrm{~b}_{1}=0.0017\end{array}$ & 0.9893 \\
\hline $\mathrm{K}_{\mathrm{D}}$ & $\ln \left(K_{D}\right)=c_{0}+c_{1} \cdot D_{0}+c_{2} \cdot S$ & $\mathrm{D}_{0}(0.0001)$ & $\begin{array}{l}\mathrm{C}_{0}=-3.7177 \\
\mathrm{C}_{1}=-0.0344 \\
\mathrm{C}_{2}=0.0006\end{array}$ & 0.9391 \\
& $\mathrm{~S}(0.0034)$ & & \\
\hline
\end{tabular}

Table 3. Medulla and cortex ratios and alginate contents in Laminaria digitata.

\begin{tabular}{llll}
\hline & $\begin{array}{l}\text { Ratio } \\
\text { (dry weight \%) }\end{array}$ & $\begin{array}{l}\text { Alginate content Distribution of the whole } \\
\text { of each kind of } \\
\text { tissue } \\
\text { (dry weight \%) }\end{array}$ & $\begin{array}{l}\text { algae alginate content in } \\
\text { each kind of tissues } \\
\text { (dry weight \%) }\end{array}$ \\
\hline Medulla & 30 & 19.8 & 46 \\
Cortex & 70 & 23.4 & 54 \\
\hline
\end{tabular}

